\title{
FORMULASI SELF-NANOEMULSIFYING DRUG DELIVERY SYSTEM (SNEDDS) EKSTRAK BIJI RAMANIA (Bouea macrophylla Griff) DENGAN ASAM OLEAT (OLEIC ACID) SEBAGAI MINYAK PEMBAWA
}

\author{
Vinny Indriani ${ }^{1, *}$, Novita Eka Kartab Putri Tobing, ${ }^{1,2}$, Laode Rijai ${ }^{1}$ \\ ${ }^{1}$ Laboratorium Penelitian dan Pengembangan Kefarmasian "Farmaka Tropis", \\ Fakultas Farmasi, Universitas Mulawarman, Samarinda, Indonesia \\ ${ }^{2}$ Kelompok Bidang Ilmu Farmasetika dan Teknologi Formulasi, Fakultas Farmasi \\ Universitas Mulawarman, Samarinda, Indonesia \\ *Email: vinny.indriany@gmail.com
}

\begin{abstract}
B.macrophylla seed extract has strong antioxidant activity but has low solubility and bioavailability. To overcome low solubility and bioavailability of B.macrophylla seed extract it was formulated into self nanoemulsifying drug delivery system (SNEDDS) using oleic acid as a carrier oil. The results showed that the most optimal composition of SNEDDS B.macrophylla seed extract consisted of a combination of tween 20 : propylenglycol : oleic acid $(0.5: 3: 1.5$ and $0.5: 3.38: 1,12)$ in $5 \mathrm{~mL}$ which has an emulsification time with an average time of 19.03 seconds and 15.2 seconds; transmittance value of $92.8 \%$ and $94.2 \%$; droplet size of $176,8 \mathrm{~nm}$ and $161,1 \mathrm{~nm}$; polidisperse index of 0,357 and 0,364; also the $\mathrm{IC}_{50}$ value of B.macrophylla seed extract $1.757 \mu \mathrm{g} / \mathrm{mL}$.
\end{abstract}

Keywords: Nanoemulsi, SNEDDS, B.macrophylla, Oleic acid

\begin{abstract}
ABSTRAK
Ekstrak biji B.macrophylla memiliki aktivitas antioksidan yang kuat namun memiliki kelarutan dan bioavailabilitas yang rendah. Meningkatkan efektivitas ekstrak biji B.macrophylla dilakukan dengan memformulasikan ke dalam sistem SNEDDS menggunakan Asam Oleat sebagai minyak pembawa. Hasil penelitian menunjukkan bahwa komposisi formula SNEDDS ekstrak biji B.macrophylla yang paling optimal terdiri dari kombinasi tween 20 : propilenglikol : asam oleat $(0,5: 3: 1,5$ dan $0,5: 3,38: 1,12)$ dalam $5 \mathrm{~mL}$ yang memiliki emulsification time dengan rerata waktu 19,03 detik dan 15,2 detik; nilai transmitansi $92,8 \%$ dan 94,2\%; ukuran tetesan 176,8 $\mathrm{nm}$ dan $161,1 \mathrm{~nm}$; polidisperse index 0,357 dan 0,364; serta nilai nilai $\mathrm{IC}_{50}$ ektrak biji B.macrophylla $1,757 \mu \mathrm{g} / \mathrm{mL}$.
\end{abstract}

Kata Kunci: Nanoemulsi, SNEDDS, B.macrophylla, Asam oleat

DOI: https://doi.org/10.25026/mpc.v8i1.334 


\section{PENDAHULUAN}

Self-Nanoemulsifying Drug

Delivery System (SNEDDS) merupakan sistem nanoemulsi yang digunakan dalam pengembangan formulasi sediaan bahan alam dengan tujuan untuk meningkatkan ketersediaan hayati zat aktif di dalam tubuh[1]. Self-Nanoemulsifying Drug Delivery System (SNEDDS) merupakan penghantaran obat dengan pembuatan campuran isotropik minyak, surfaktan, kosurfaktan dan obat yang mampu membentuk nanoemulsi minyak dalam air secara spontan di dalam saluran cerna dan menghasilkan ukuran tetesan yang berukuran nanometer[2][3]. Berdasarkan penelitian sebelumnya, formulasi SelfNanoemulsifying Drug Delivery System (SNEDDS) ketoprofen dengan menggunakan asam oleat, tween 20 dan propilen glikol menghasilkan nanoemulsi dengan ukuran tetesan 25,6 $\mathrm{nm}$, waktu dispersi 36,04 detik serta stabil selama 24 jam dalam media AGF (Artificial Gastric Fluid) dan AIF (Artificial Intestinal Fluid)[4].

B.macrophylla merupakan bahan alam yang banyak mengandung senyawa metabolit sekunder flavonoid antosianin yang dikenal sebagai senyawa antioksidan, umumnya ekstrak B.macrophylla memiliki kelarutan dan bioavailabilitas yang rendah sehingga memerlukan dosis yang cukup besar untuk mencapai efektivitas terapi yang maksimal [5]. Berdasarkan penelitian sebelumnya, ekstrak biji B.macrophylla menunjukkan aktivitas antioksidan dengan nilai $\mathrm{IC}_{50}$ sebesar $2,25 \mathrm{mg} / \mathrm{ml}[6]$.

Berdasarkan data-data penelitian yang ada maka dibuatlah formulasi sediaan dari ekstrak biji B.macrophylla dengan menggunakan SelfNanoemulsifying Drug Delivery System (SNEDDS) untuk memaksimalkan kelarutan dan bioavailabilitas ekstrak biji B.macrophylla didalam tubuh.

\section{METODE PENELITIAN}

\begin{abstract}
Alat dan Bahan
Alat yang digunakan dalam penelitian ini yaitu timbangan analitik, mangkok kaca, toples kaca, rotary evaporator, waterbath, corong Bucher, kuvet, vortex, spektrofotometer $U V$ Visibel, tabung reaksi, rak tabung reaksi, labu ukur, mikropipet, propipet, botol vial, pipet tetes, gelas kimia, gelas ukur, batang pengaduk, spatel, centrifuge, magnetic stirer, stirer bar, sonikator, termometer, $\mathrm{pH}$ meter, stopwatch, dan Particle Size Analyzer (PSA).

Bahan yang digunakan dalam penelitian ini yaitu biji ramania, methanol for analysis, methanol, aquadest, aqua de ion, kertas saring, asam oleat (oleic acid), propilenglikol, tween-20, $\mathrm{CaCl}_{2}, \mathrm{HCl}$ $37 \%, \mathrm{KCl}, \mathrm{MgCl}_{2}, \mathrm{NaCHO}_{3}, \mathrm{NaCl}$, dan 1,1-Diphenyl-2-Picrylhydrazil (DPPH).
\end{abstract}

\section{Ekstraksi}

Sampel biji ramania (Bouea macrophylla Griff) diperoleh dari kelurahan Gunung Lingai, kecamatan Sungai Pinang, Kota Samarinda, Provinsi Kalimantan Timur, Indonesia. Biji B.macrophylla yang diambil sebanyak 5 kg disortasi basah, biji B.macrophylla kemudian dicuci dan dirajang kemudian dikeringkan setelah itu ditimbang dan dikecilkan ukurannya. Biji B.macrophylla dimaserasi menggunakan pelarut metanol. Sampel kemudian disaring dan larutan ekstrak yang diperoleh di uapkan menggunakan rotary evaporator pada suhu $55^{\circ} \mathrm{C}$ hingga diperoleh ekstrak kental.

\section{Uji Aktivitas Antioksidan}

Ekstrak biji B.macrophylla ditimbang sebanyak 0,01 gram dilarutkan dalam methanol for analysis. Pembuatan seri konsentrasi dengan cara membuat larutan stok 10 ppm kemudian diencerkan pada konsentrasi 1 ppm, 1,5 ppm, dan 2 ppm. Pembuatan stok DPPH $40 \mathrm{ppm}$ dilakukan dengan menimbang 0,002 
gram kristal DPPH yang dilarutkan dalam methanol for analysis. Pengukuran aktivitas antioksidan dilakukan dengan menggunakan alat spektrofotometer $U V$ Visibel. Setelah itu ditentukan persamaan regresi linear, persen inhibisi antioksidan, dan nilai $\mathrm{IC}_{50}$.

\section{Uji Kelarutan Pembawa}

Sebanyak 0,01 gram ekstrak metanol biji B.macrophylla ditambahkan kedalam masing-masing pembawa (oleic acid, olive oil, VCO, cremophor RH-40, tween-20, tween-80, propilenglikol, dan PEG 400). Campuran ini dikondisikan dalam waterbath pada suhu $40^{\circ} \mathrm{C}$ selama 10 menit. Proses pelarutan ekstrak dalam pembawa dimaksimalkan dengan alat sonikator selama 16 menit lalu disentrifugasi pada $3000 \mathrm{rpm}$ selama 20 menit. Supernatan diambil dan diukur konsentrasinya dengan spektrofotometer $U V$-Visible pada panjang gelombang maksimum biji B.macrophylla.

\section{Formulasi SNEDDS}

Penentuan komposisi diawali dengan merancang komposisi minyak, surfaktan, dan kosurfaktan. Setiap formula dibuat sebanyak $5 \mathrm{~mL}$ dalam botol vial. Campuran dihomogenkan dengan bantuan magnetic stirer selama 30 menit, sonikator selama 16 menit dan dikondisikan dalam waterbath pada suhu $45^{\circ} \mathrm{C}$ selama 10 menit. Hasil pencampuran didiamkan selama 24 jam pada suhu ruangan (tidak terkontrol) untuk dilihat homogenitasnya. Formula paling stabil (jernih dan homogen) merupakan formula yang dipilih untuk diformulasikan kembali dengan penambahan ekstrak biji B.macrophylla 0,01 gram. Setelah ekstrak biji B.macrophylla larut sempurna dalam fase minyak lalu kemudian dicampurkan dengan fase air.

\section{Evaluasi SNEDDS}

\section{Pengamatan Emulsification Time}

Pengamatan emulsification time dilakukan terhadap nanoemulsi ekstrak dalam tiga media yaitu aquades, (artificial gastric fluid) AGF tanpa pepsin, dan (artificial intestinal fluid) AIF tanpa pankreatin. Media sebanyak $100 \mathrm{~mL}$ dikondisikan pada suhu $37^{\circ} \mathrm{C}$ diatas magnetic stirrer dengan kecepatan $120 \mathrm{rpm}$. SNEDDS yang berisi ekstrak B.macrophylla sejumlah $1 \mathrm{~mL}$ diteteskan ke dalam media secara cepat. Nanoemulsi yang terbentuk, ditandai dengan terlarutnya SNEDDS ekstrak secara sempurna dalam media[3][7].

\section{Pengukuran Nilai Transmitansi}

Sebanyak $10 \mathrm{~mL}$ formula SNEDDS yang telah diemulsikan kemudian diukur transmitansinya menggunakan spektrofotometer $U V$ Visible pada panjang gelombang $650 \mathrm{~nm}$ dengan blanko aquades untuk mengetahui tingkat kejernihannya. Semakin jernih atau transmitansi semakin mendekati transmitansi aquades maka diperkirakan tetesan emulsi telah mencapai ukuran nanometer[3][7].

\section{Penentuan Ukuran dan Distribusi Partikel serta Potensial Zeta}

Penentuan dilakukan dengan pengukuran menggunakan Particle Size Analyzer (PSA). Sebanyak 2 tetes sampel nanoemulsi dicampur kedalam $5 \mathrm{~mL}$ aquades, diambil $3 \mathrm{~mL}$ dan dimasukkan ke dalam kuvet untuk dianalisis.

\section{HASIL DAN PEMBAHASAN}

\section{Ekstraksi Biji B.macrophylla}

$$
\text { Jumlah simplisia }
$$

biji

B.macrophylla yang diperoleh setelah melalui tahap pengolahan memiliki bobot 231 gram. Pemilihan metode ekstraksi didasarkan atas sensitivitas senyawa antioksidan terhadap suhu yang tinggi. Proses ekstraksi dilakukan dengan 
menggunakan pelarut metanol yang memiliki kemampuan menyari senyawa nonpolar sampai dengan polar. Persentase rendemen ekstrak biji B.macrophylla dapat dilihat pada Tabel 1 .

\section{Aktivitas Antioksidan Ekstrak Biji B.macrophylla}

Pengujian aktivitas antioksidan ekstrak metanol biji B.macrophylla dilakukan dengan menggunakan metode DPPH (1,1-Diphenyl-2-Picrylhydrazil) secara kuantitatif menggunakan spektrofotometer $U V$-Visible pada panjang gelombang $513 \mathrm{~nm}$. Hasil uji aktivitas antioksidan ekstrak B.macrophylla diperoleh hasil seperti pada Tabel 2.

Parameter yang dipakai untuk menunjukkan aktivitas antioksidan adalah Inhibition Concentration ( $\mathrm{IC}_{50}$ ) yaitu konsentrasi suatu zat antioksidan yang memberikan penghambatan 50\%. Semakin kecil nilai $\mathrm{IC}_{50}$ berarti aktifitas antioksidannya semakin tinggi. Nilai IC $_{50}$ diperoleh berdasarkan perhitungan persamaan regresi linear dari kurva absorbansi sampel. Kurva absorbansi ekstrak biji B.macrophylla dapat dilihat pada Gambar 1.

Suatu senyawa dikatakan sebagai antioksidan sangat kuat apabila nilai $\mathrm{IC}_{50}$ kurang dari $50 \mu \mathrm{g} / \mathrm{mL}$, kuat apabila nilai $\mathrm{IC}_{50}$ antara $50-100 \mu \mathrm{g} / \mathrm{mL}$, sedang apabila nilai $\mathrm{IC}_{50}$ berkisar antara $100-150 \mu \mathrm{g} / \mathrm{mL}$, dan lemah apabila nilai $\mathrm{IC}_{50}$ berkisar antara $150-200 \mu \mathrm{g} / \mathrm{mL}$ [8]. Nilai IC $_{50}$ ektrak biji B.macrophylla adalah 1,757 $\mu \mathrm{g} / \mathrm{mL}$ yang memiliki aktivitas antioksidan yang tergolong sangat kuat.

\section{Kelarutan Pembawa Ekstrak Biji B.macrophylla}

Pemilihan larutan pembawa dalam formulasi SNEDDS sangat penting untuk menghindari adanya pengendapan obat ketika berada di lumen usus. Hasil uji kelarutan ekstrak biji B.macrophylla dalam berbagai pembawa (fase minyak, surfaktan, dan kosurfaktan) diperoleh hasil seperti pada Tabel 3.

Hasil uji kelarutan menunjukkan bahwa asam oleat lebih banyak melarutkan ekstrak biji B.macrophylla dibandingkan minyak zaitun dan minyak kelapa. Asam oleat merupakan asam lemak tak jenuh yang memiliki satu buah ikatan rangkap. Peningkatan kelarutan ini diperkirakan karena polaritas asam oleat yang tinggi. Hasil pengujian kelarutan untuk pemilihan surfaktan menunjukkan kelarutan ekstrak biji B.macrophylla lebih besar dalam tween 80 dibanding tween 20 dan cremophor RH-40. Hal ini membuktikan bahwa tween 80 lebih "like dissolve like" terhadap ekstrak biji B.macrophylla. Hasil uji kelarutan untuk pemilihan kosurfaktan menunjukkan ekstrak biji B.macrophylla lebih larut dalam propilenglikol dibanding PEG 400. Hal tersebut mengindasikan bahwa polaritas propilenglikol lebih menyamai ekstrak biji B.macrophylla.

\section{Formulasi SNEDDS}

Penentuan komposisi fase air, fase minyak, surfaktan, dan kosurfaktan adalah dengan menentukan komposisi yang stabil dan homogen. Hasil penentuan komposisi sediaan dapat dilihat pada Tabel 4, Tabel 5, dan Tabel 6.

Hasil penentuan komposisi surfaktan dan kosurfaktan pada Tabel 4. menunjukkan komposisi tween 20 dan tween 80 mampu membentuk campuran yang homogen dari kosurfaktan yaitu propilenglikol. Komposisi surfaktan sangat mempengaruhi stabilitas campuran, semakin banyak surfaktan maka campuran akan semakin jernih. Berdasarkan Tabel 5. kombinasi tween 20 dengan propilenglikol lebih mampu menghasilkan campuran yang homogen pada penambahan asam oleat dibandingkan pada penggunaan tween 80 dengan propilenglikol. Hal ini dikarenakan tween 20 dan propilenglikol mempunyai bobot molekul dan viskositas 
yang lebih rendah dan struktur yang lebih sederhana dibandingkan tween 80 dan propilenglikol, sehingga dapat lebih mudah berinteraksi dengan kandungan ekstrak.

Asam oleat sebagai fase minyak diharapkan mampu memerangkap ekstrak biji B.macrophylla dalam sediaan nanoemulsi. Asam oleat memiliki nilai $\log \mathrm{P}$ sebesar 6,5 sehingga asam oleat akan semakin mudah berikatan dengan gugus lipofilik senyawa lain. Rasio komposisi minyak dengan surfaktan dan kosurfaktan berada pada perbandingan 1:9, hal ini dikarenakan jumlah surfaktan dan kosurfaktan harus lebih banyak dari jumlah minyaknya agar mampu melingkupi tetesan minyak saat teremulsi di dalam air dan menghasilkan ukuran tetesan dalam rentang nanometer[9].

Tabel 1. Hasil Perhitungan Rendemen Ekstrak

\begin{tabular}{cc}
\hline Sampel & Jumlah $($ gram/\%) \\
\hline Simplisia Kering & 231 gram \\
Maserasi & 39,73 gram \\
Re-Maserasi 1 & 14,5 gram \\
Re-Maserasi 2 & 3,3 gram \\
\hline Rendemen Total & $24,90 \%$ \\
\hline
\end{tabular}

Tabel 2. Hasil Pengujian Aktifitas Antioksidan

\begin{tabular}{cccc}
\hline $\begin{array}{c}\text { Konsentrasi } \\
(\mathrm{ppm})\end{array}$ & $\begin{array}{c}\text { Absorbansi (A) } \\
\lambda=514 \mathrm{~nm}\end{array}$ & Aktifitas Antioksidan $(\%)$ & Nilai IC $_{50}(\mu \mathrm{g} / \mathrm{ml})$ \\
\hline Blanko & 0,848 & & \\
1 & 0,667 & 21,344 & \\
1,5 & 0,498 & 41,273 & 1,757 \\
2 & 0,351 & 58,608 & \\
\hline
\end{tabular}

Tabel 3. Hasil Uji Kelarutan dalam Pembawa

\begin{tabular}{lc}
\hline \multicolumn{1}{c}{ Pembawa } & Kelarutan $(\mu \mathrm{g} / \mathrm{mL})$ \\
\hline Oleic Acid & $39,434 \mu \mathrm{g} / \mathrm{mL}$ \\
Virgin Coconut Oil & $38,282 \mu \mathrm{g} / \mathrm{mL}$ \\
Olive Oil & $36,295 \mu \mathrm{g} / \mathrm{mL}$ \\
Cremophor RH-40 & $35,871 \mu \mathrm{g} / \mathrm{mL}$ \\
Tween-20 & $40,630 \mu \mathrm{g} / \mathrm{mL}$ \\
Tween-80 & $41,109 \mu \mathrm{g} / \mathrm{mL}$ \\
Propilenglikol & $42,408 \mu \mathrm{g} / \mathrm{mL}$ \\
PEG 400 & $41,610 \mu \mathrm{g} / \mathrm{mL}$ \\
\hline
\end{tabular}


Formulasi Self-Nanoemulsifying Drug Delivery System (SNEDDS) Ekstrak Biji Ramania (Bouea macrophylla Griff) dengan Asam Oleat (Oleic Acid) sebagai Minyak Pembawa

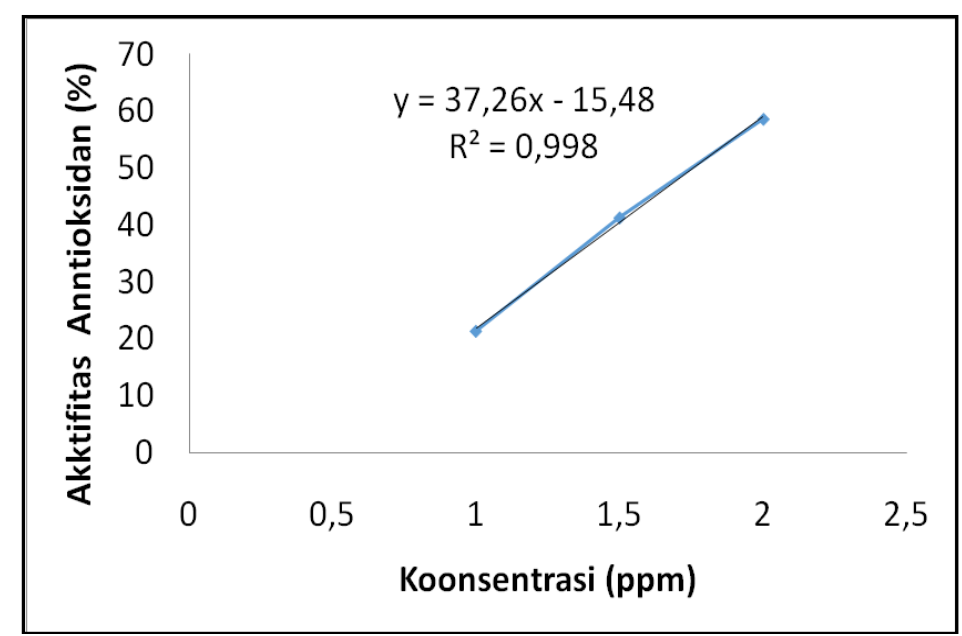

Gambar 1. Kurva Absorbansi Ekstrak Biji B.macrophylla

Tabel 4. Hasil Formulasi Surfaktan dan Kosurfaktan

\begin{tabular}{ccc}
\hline Rasio Komposisi & \multicolumn{2}{c}{ Hasil } \\
\cline { 2 - 3 } Surfaktan : Kosurfaktan & T80:PG & T20 : PG \\
\hline $1: 1$ & $\sqrt{ }$ & $\sqrt{ }$ \\
$2: 1$ & $\sqrt{ }$ & $\sqrt{ }$ \\
$3: 1$ & $\sqrt{ }$ & $\sqrt{ }$ \\
$3: 2$ & $\sqrt{ }$ & $\sqrt{ }$ \\
$2: 3$ & $\sqrt{ }$ & $\sqrt{ }$ \\
$1: 3$ & $\sqrt{ }$ & $\sqrt{ }$ \\
$1: 2$ & $\sqrt{ }$ & \\
Keterangan $:$ Surfaktan $=$ T80 (tween 80), T20 (tween 20); Kosurfaktan = PG \\
(propyleneglycol); $\sqrt{ }=$ homogen; X= memisah (dalam 24 jam)
\end{tabular}

Tabel 5. Hasil Formulasi Minyak dengan Surfaktan dan Kosurfaktan

Rasio Komposisi

Surfaktan :

Kosurfaktan
Hasil Rasio Komposisi

Minyak : Surfaktan-Kosurfaktan

\begin{tabular}{ccc} 
& OA : T80- & OA $:$ T20-PG \\
\hline $1: 1$ & PG & $\sqrt{ }$ \\
$2: 1$ & $\sqrt{ }$ & $\sqrt{ }$ \\
$3: 1$ & $\sqrt{ }$ & $\sqrt{ }$ \\
$3: 2$ & $\sqrt{ }$ & $\mathrm{X}$ \\
$2: 3$ & $\mathrm{X}$ & $\mathrm{X}$ \\
$1: 3$ & $\mathrm{X}$ & $\mathrm{X}$ \\
$1: 2$ & $\mathrm{X}$ & $\mathrm{T} 20(\mathrm{twen} 20)$ \\
\hline
\end{tabular}

Keterangan : Surfaktan $=$ T80 (tween 80), T20 (tween 20); Kosurfaktan = PG (propyleneglycol), OA (asam oleat); $\sqrt{ }=$ homogen; $X=$ memisah (dalam 24 jam) 
Tabel 6. Hasil Formulasi Air dengan Minyak, Surfaktan, dan Kosurfaktan

\begin{tabular}{ccc}
\hline $\begin{array}{c}\text { Rasio Komposisi } \\
\text { Surfaktan : Kosurfaktan }\end{array}$ & \multicolumn{2}{c}{ Hasil Emulsifikasi } \\
& Fase Minyak : Fase Air $(1: 5)$ \\
\hline $1: 1$ & OA : T80-PG & OA : T20-PG \\
$2: 1$ & $\mathrm{X}$ & $\mathrm{X}$ \\
$3: 1$ & $\mathrm{X}$ & $\sqrt{ }$ \\
$3: 2$ & $\mathrm{X}$ & $\mathrm{X}$ \\
$2: 3$ & $\mathrm{X}$ & $\mathrm{X}$ \\
$1: 3$ & $\mathrm{X}$ & $\mathrm{X}$ \\
$1: 2$ & $\mathrm{X}$ & $\mathrm{X}$ \\
\hline
\end{tabular}

Keterangan : Surfaktan $=$ T80 (tween 80$),$ T20 (tween 20); Kosurfaktan = PG (propyleneglycol), OA (asam oleat); $\sqrt{ }=$ homogen; $X=$ memisah (dalam 24 jam)

Tabel 7. Hasil Pengamatan Emulsification Time

\begin{tabular}{ccc}
\hline Formula Optimal & Media & Emulsification Time $($ detik $)(\mathrm{x} \pm \mathrm{sd})$ \\
\hline \multirow{3}{*}{$2: 1$} & Aquades & $17,79 \pm 0,05$ \\
& AGF & $21,54 \pm 0,13$ \\
& AIF & $17,78 \pm 0,29$ \\
\hline \multirow{3}{*}{$3: 1$} & Aquades & $13,60 \pm 0,31$ \\
& AGF & $17,74 \pm 0,19$ \\
& AIF & $14,26 \pm 0,38$ \\
\hline
\end{tabular}

Tabel 8. Hasil Pengukuran Transmitansi

\begin{tabular}{ccc}
$\begin{array}{c}\text { Rasio Komposisi } \\
\text { urfaktan : Kosurfaktan }\end{array}$ & $\begin{array}{c}\text { Rasio Komposisi } \\
\text { Minyak : Surfaktan-Kosurfaktan }\end{array}$ & $\begin{array}{c}\text { Transmitansi } \\
(\mathrm{x} \pm \mathrm{sd})\end{array}$ \\
\hline $2: 1$ & $1: 9$ & $92,8 \pm 0,3$ \\
\hline $3: 1$ & $1: 9$ & $94,2 \pm 0,7$ \\
\hline
\end{tabular}

Tabel 9. Hasil Penentuan Ukuran Nanoemulsi

\begin{tabular}{ccc}
\hline Formula Optimal & Ukuran Tetesan $(\mathrm{nm})$ & Polydispersity index $(P I)$ tetesan \\
\hline $2: 1$ & 176,8 & 0,357 \\
\hline $3: 1$ & 161,1 & 0,364 \\
\hline
\end{tabular}

Hasil emulsifikasi pada Tabel 6. menunjukkan formula paling stabil dan homogen ialah formula dengan perbandingan surfaktan dan kosurfaktan 3:1 dan 2:1.

\section{Evaluasi SNEDDS}

\section{Pengamatan Emulsification Time}

Hasil penentuan emulsification time dapat dilihat pada Tabel 7. dengan hasil formula SNEDDS mampu larut dalam setiap medium kurang dari 5 menit. Syarat emulsification time untuk 
sediaan SNEDDS yaitu kurang dari 5 menit. Pembentukan nanoemulsi dalam tiap media terjadi karena ada surfaktankosurfaktan yang dapat menurunkan tegangan antar muka dari air dan minyak[10].

\section{Pengukuran Nilai Transmitansi}

Nilai transmitansi (T\%) diperoleh melalui pengamatan secara turbidimetri (kekeruhan) dengan replikasi uji sebanyak 3 kali. Hasil pengukuran nilai transmitansi setiap formula dapat dilihat pada Tabel 8. Suatu formula nanoemulsi yang baik akan memiliki visual yang jernih dengan transmitansi $>90 \%[11]$.

\section{Penentuan Ukuran dan Distribusi Partikel serta Potensial Zeta}

Hasil uji menggunakan particle size analyzer (PSA) menunjukkan hasil ukuran partikel sebesar $176,8 \mathrm{~nm}$ dan 161,1 nm. Hal ini menunjukkan bahwa ukuran tetesan mikroemulsi telah dapat dikatakan berukuran mikrometer yakni $50 \mathrm{~nm}-500 \mathrm{~nm}$. Nilai polydispersity index (PI) kurang dari 1 (0,357 dan 0,364) berfungsi sebagai indikator distribusi ukuran yang homogen. Hal ini menunjukkan bahwa metode pembuatan SNEDDS yang digunakan untuk preparasi nanoemulsi memiliki reliabilitas yang baik[10].

\section{KESIMPULAN}

Formula SNEDDS ekstrak biji B.macrophylla yang paling optimal terdiri dari kombinasi tween 20 : propilenglikol : asam oleat $(0,5: 3: 1,5$ dan $0,5: 3,38: 1,12$ ) dalam $5 \mathrm{~mL}$ yang memiliki emulsification time dengan rerata waktu 19,03 detik dan 15,2 detik; nilai transmitansi $92,8 \%$ dan $94,2 \%$; ukuran tetesan $176,8 \mathrm{~nm}$ dan $161,1 \mathrm{~nm}$; polidisperse index 0,357 dan 0,364; serta nilai nilai $\mathrm{IC}_{50}$ ektrak biji B.macrophylla $1,757 \mu \mathrm{g} / \mathrm{mL}$.

\section{DAFTAR PUSTAKA}

[1] Lovelyn C, Attama AA. 2011. Current State of Nanoemulsions in Drug Delivery. J Biomater Nanobiotechnol 2 :626-639.

[2] Makadia H. A., Bhatt A. Y., Parmar R. B., Paun J. S., dan Tank H. M., 2013. Self Nanoemulsifying Drug Delivery System (SNEDDS): Future Aspects, Asian J Pharm Res, 3(1): 21-24.

[3] Patel, J., Kevin, G., Patel, A., Raval, M., dan Sheth, N., 2011a , Design and Development of a SelfNanoemulsifying Drug Delivery System for Telmisartan for Oral Drug Delivery, Int J Pharm Investig, 1: 112-118.

[4] Surya, E.R.. 2014. Pembuatan SSNEDDS Ketoprofen dengan Asam Oleat sebagai Fase Minyak, Tween 20 Sebagai Surfaktan, dan Propilen Glikol sebagai Kosurfaktan. Skripsi. Fakultas Farmasi Universitas Gadjah Mada. Yogyakarta.

[5] Londo, Nita, Eva Johannes, Hasnah Natsir, dan Sri Suhadiyah. 2015. Bioaktifvtas Ekstrak Kasar Biji Gandaria (Bouea macrophylla Griff) sebagai Bahan Antioksidan. Jurusan Biologi FMIPA Universitas Hasanuddin.

[6] Hanifa, Dini, dan Yasmiwar Susilawati. 2017. Review Artikel: Potensi Tanaman Gandaria (Bouea macrophylla Griff) Sebagai Obat Herbal yang Beraktivitas Antioksidan. Farmaka, Volume 15, Nomor 3.

[7] Patel, J., Patel, A., Raval, M., dan Sheth, N., 2011b , Formulation and Development of a SelfNanoemulsifying Drug Delivery System of Irbesartan, $J$ Adv Pharm Technol Res, 2: 9-16.

[8] Molyneux, P. 2004. The Use of Stable Free Radical Diphenylpicrylhydrazyl (DPPH) or Estimating Antioksidan Activity. Songklanakarin J SchiTechnol. 
[9] Indratmoko, S. 2014. Pengembangan Nanopartikel Ekstrak temulawak (Curcuma xanthorrhiza, Roxb) dengan Teknik Self Nanoemulsifying Drug Delivery System (SNEDDS) Menggunakan Fase Minyak Ikan Cucut Botol (Centrocymnus crepidater) sebagai Obat Antiinflamasi, Tesis, Universitas Gadjah Mada, Yogyakarta.

[10] Meirista, Indri., 2014, Formulasi dan Uji Aktivitas Nano-Herbal AntiHiperkolestrol dari Kombinasi
Ekstrak Temulawak (Curcuma xanthorrhiza Roxb.) Dan Sambung Nyawa (Gynura Procumbens (Lour.) Merr.) Menggunakan Myritol 318 sebagai Fase Minyak. Tesis. Farmasi. Yogyakarta : UGM.

[11] Costa, J.A., Lucas, E.F., Queiros, Y.G.C., dan Mansur, C.R.E. 2012, Evaluation of nanoemulsions in the cleaning of polymeric resins. Colloids Surf. Physicochem. Eng. Asp. 415, 112-118. Doi: 10.1016/j.colsurfa.2012.10.0011. 